\title{
An Effective and Way Forward Approach for Road Safety Acquisition of Knowledge - Correlative Study for Pakistan
}

\author{
Syed Faraz Jafri \\ Department of Civil Engineering, Sir Syed University of Engineering and Technology, Karachi, Pakistan \\ E-mail: engr_sfjafri@hotmail.com
}

\begin{abstract}
It is an unfortunate fact that two major issues including health and safety are not given as much importance as the issue persists. In this context road safety is also another important agenda for the developing countries and the situation has become worsened particularly in Pakistan. Under the umbrella of Pakistan, various metropolitan cities are lying that are facing the common problems of road safety. All modes of transportation and eventually all users including rider, pillion rider, drivers, passengers and pedestrians are the common players of road environment in Karachi City (a metropolitan city of Pakistan). Apart from that the majority of the population travels in public transport. As per the statistics, approximately $30 \%$ to $45 \%$ people are associated with the existing public transport network and in the same way the list of problems grasping traffic crashes is concerned with this network as well. According to a study, three E's of transportation including Education, Engineering and Enforcement should be correlated with each other for an effective, efficient and balanced system. The road users are not well aware of the basic, standard and updated road safety knowledge that ultimately brings no prolonging effect on the Engineering and Enforcement subsidiary. The least important parameter should be more enhanced and accomplished which is basically the education of road safety knowledge. The paper reveals the collected information based on the designed questionnaire capturing the features of limited road safety knowledge of drivers and riders in continuation with the traffic crash dependent factors. Based on the analytical facts and figures, the research study focused on major recommendations transferring the acquisition of engineering and enforcement measures with the initiation of fundamental understanding of prevention of crashes. The system should not be designed in a manner that gives the lesson of enforcement only; it needs a balanced approach which is only possible by featuring the existing and available approaches of the city.
\end{abstract}

Keywords: Safety, enforcement, road user, Pakistan.

ENGINEERING JOURNAL Volume 17 Issue 1

Received 1 July 2012

Accepted 5 September 2012

Published 1 January 2013

Online at http://www.engj.org/

DOI:10.4186/ej.2013.17.1.41 


\section{Inadequate Traffic Planning and Road Crash Hierarchy}

Inadequacy of traffic planning is rising day by day, and due to this reason people lose their precious lives or suffer temporary and permanent injuries. A significant growth of population in developing countries is directly proportional to the traffic chaos; these dilemmas will be extremely hazardous and risky when there is lack of checking and balancing from the traffic law enforcement agencies [1]. Investigation has shown that many domestic rules and regulation for traffic safety are just only at the documented stage, but people in general are not aware of its existence. Awareness programs and training sessions for the targeted road user should be the stringent approach; it might be helpful for the fulfillment of several issues including understanding for traffic laws, safety signs, vehicle ordinance and manufacturing details and road/ environmental conditions [2]. Karachi is one of the most important cities of Pakistan and a world famous city in terms of population, economic potential and geo-strategic location [3].

Based on the statistics, the population of Karachi is tremendously increased in last decade, because people migrated all around the Pakistan to Karachi. However, they suffer from multiple issues including unemployment, lack of education facilities, inappropriate accommodation and even not having medical advancement in their cities. Within the domain of these issues, they need to live with the miserable conditions of traffic and transportation. It is linked with the inadequate system master planning resulting in the unfortunate mishaps of traffic accidents. Karachi is enriched with the number of locations that are to be nominated as the black spots of the city carrying a meaningful percentage of minor, serious and fatal injuries.

\section{Scope and Objectives of Entire Research}

The scope of this work for the relevant study is restricted to the strong manipulation of road safety acquirement of knowledge. The study is focused on the development and generation of ideas for the stakeholders at micro and macro levels. The following are some of the concerned objectives of this research paper:

- Identification of traffic safety problems on selected arterials of Karachi;

- Idealizing the correlation factor between three E's of transportation through detailed survey methodology;

- Highlighting the significance of road safety awareness;

- Formulization of effective transport planning based on incident prevention.

\section{Incident Approach and Traffic Safety Analysis}

The respective approach is associated with the solution for the problems which are not readily available as innovative work needs to be done to arrive at new policies and design. It is quite evident that the understanding and scientific approach might be shared internationally but it needs to be molded based on the location specific and context sensitive. As mentioned earlier that the subject should be treated as the public health problem catering low cost solutions for different arterials. The identified treatments are to be enlisted on short term as well as long term planning [1].

\section{Injury Control Trends (Mitigation between Developed and Developing Countries)}

During the last three decades, there is the meaningful reduction of traffic crash fatalities and injuries. The reason behind this is the standards instituted for vehicles, roads and highway furniture is approached that are prevalent to those societies. Less-motorized country societies have been seriously concerned with the significant loss of lives due to road crashes for more than a decade. One of the major flaw resists is the strong applicability of theoretical basis of road traffic injury control but not the actual and physical solutions. The applications and results may not be of similar magnitude in high income and low income countries; they are dependent on the living condition and existing road infrastructure. The decision makers and international consultants come from a different stratum of society. They have an imprint of the prevailing socio-economic situation embedded in them [4]. According to a study of crashes related to developed and developing countries, the percentage of road users killed is categorized. In the available data, 
Pakistan's situation is embedded for having a clear perspective. The idea is more enhanced in the following Table [2].

Table 1. Percentage of road users killed in various modes of transport as the population of all fatalities [2, 4].

\begin{tabular}{lcccr}
\hline Countries & Pedestrians & Riders & Four wheelers & Others \\
\hline Australia & $18 \%$ & $10 \%$ & $65 \%$ & $7 \%$ \\
Japan & $28 \%$ & $21 \%$ & $41 \%$ & $10 \%$ \\
Malaysia & $15 \%$ & $57 \%$ & $18 \%$ & $10 \%$ \\
Netherlands & $10 \%$ & $12 \%$ & $56 \%$ & $22 \%$ \\
Norway & $15 \%$ & $12 \%$ & $65 \%$ & $8 \%$ \\
Thailand & $10 \%$ & $73 \%$ & $13 \%$ & $4 \%$ \\
USA & $12 \%$ & $5 \%$ & $80 \%$ & $3 \%$ \\
Delhi, India & $42 \%$ & $28 \%$ & $14 \%$ & $16 \%$ \\
Bandung, Indonesia & $33 \%$ & $41 \%$ & $17 \%$ & $9 \%$ \\
Colombo, Sirilanka & $39 \%$ & $35 \%$ & $14 \%$ & $12 \%$ \\
Karachi, Pakistan & $\mathbf{4 8 \%}$ & $\mathbf{4 7 \%}$ & $\mathbf{4 7 \%}$ & $\mathbf{1 0} \%$ \\
\hline
\end{tabular}

On the overlook of the data presented in the above Table, it can be predicted that riders and pedestrians or passengers are the vulnerable road users for the city of Karachi. This proves that the majority of low income population is willing to ride but due to the negligence and lack of subsequent knowledge leading towards traffic crashes.

\section{Practical Condition of Road Safety on Major Arterials of Karachi}

Alost more than 15 arterials or major locations of respective towns are surveyed during the whole research in order to achieve all road and safety parameters. For illustration, the idea is visualized through the following figures.
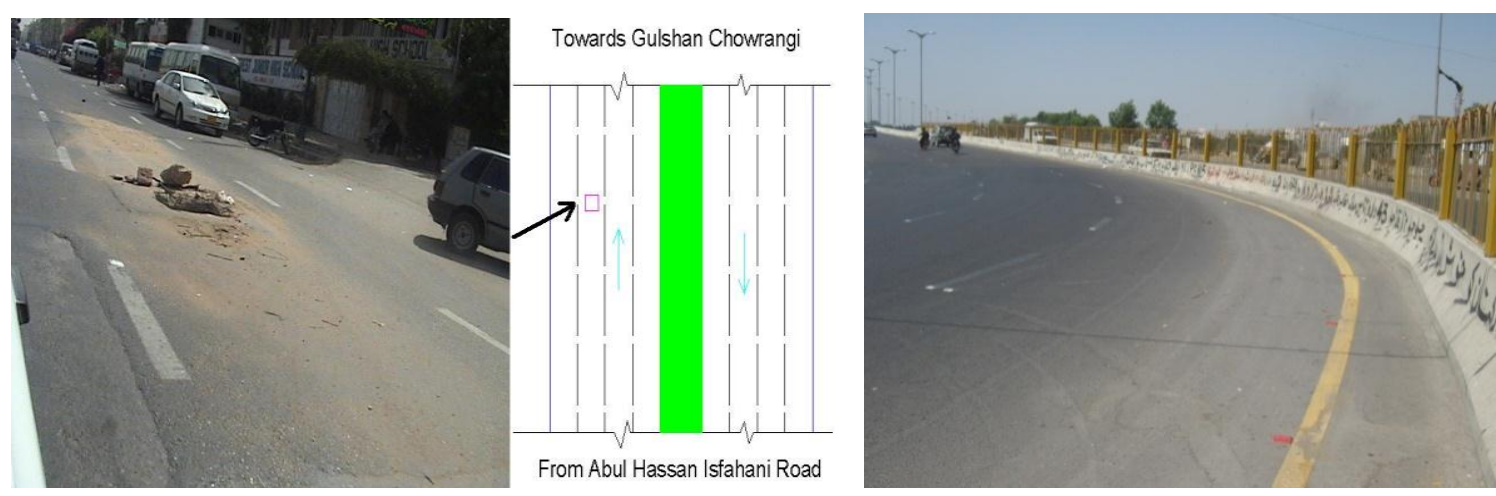

Fig. 1. Open manholes on busy collectors (left) and sharp horizontal curves with no safety measures (right).

On the respective locations, two important issues are focused that are inadequate road maintenance problems and lack of engineering measures. The system needs to show demand oriented by strong routine and periodic maintenance. Moreover, the horizontal curves are hazardous for the riders and pillion riders due to slippage effects. Special warning signs are to be posted on these locations while super elevation design philosophy should be on a prior basis. As the prime subject of paper, the road safety knowledge to each type of road user is mandatory. But unfortunately the existing system of Karachi is lacking behind this as shown below. 

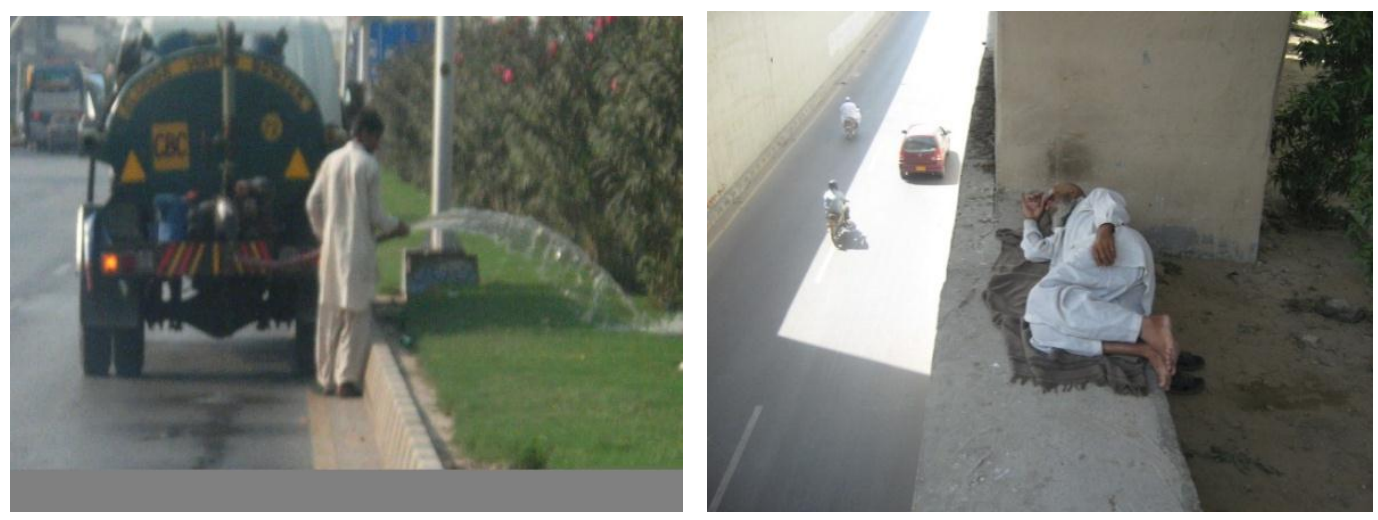

Fig. 2. Horticulture action (left) and dangerous act by road user (right).

Normally, the horticulture action is imposed within the limited time slots but it is to be furnished in the dawn and daylight timings in which high traffic intensity is present. Apart from that, in the adjacent picture the person is at his own risk, sleeping at the edge of parapet wall following the underpass wall. Here the road user is not well aware of the basic understanding, although some engineering measures might be introduced in the form of rising brick wall or some other physical measure. A number of other problems are gathered from the surveyed locations including lack of pedestrian facilities, parking facilities, absence of signified traffic signs, improper and absence of road furniture, insufficient illumination and road distresses etc.

\section{Research Methodology with Analytical Facts and Figures (Road and Human Contributory Factors)}

At the initial steps of research, a detailed questionnaire was designed including the basic and traffic related questions (as shown below). It was designed in a manner to expect from the respondent, two major entities that are basic road safety knowledge at the level of beginner and crash prevention control for his/her entire life. In order to eliminate the noise in data, the locations visited are Quaidabad, Landhi, Malir City, Gulistan-e-Jauhar, Gulshan-e-Iqbal Town, New Karachi, North Karachi, Ornagi Town, North Nazimabad, Lyari, Saddar town and Mehmoodabad. The locations are selected on the basis of past knowledge and severity of arterial depending on the existing traffic stream. 
Table 2. Design questionnaire with assign code.

\begin{tabular}{|c|c|c|c|c|c|}
\hline \multicolumn{6}{|c|}{ Traffic Survey Questionnaire (Karachi) } \\
\hline $\begin{array}{l}\text { S. } \\
\text { No. }\end{array}$ & Questions & $\begin{array}{l}\text { Question } \\
\text { Code }\end{array}$ & $\begin{array}{l}\text { Answer } \\
\text { Description }\end{array}$ & $\begin{array}{l}\text { Number of } \\
\text { Persons } \\
\text { Lying in } \\
\text { Following } \\
\text { Section }\end{array}$ & $\begin{array}{c}\text { Total } \\
\text { Number } \\
\text { of } \\
\text { Persons }\end{array}$ \\
\hline \multirow{6}{*}{1} & \multirow{6}{*}{ Age Group? } & \multirow{6}{*}{ A } & 18 to 25 (Years) & 115 & \multirow{6}{*}{450} \\
\hline & & & 26 to 32 (Years) & 95 & \\
\hline & & & 33 to 39 (Years) & 70 & \\
\hline & & & 40 to 46 (Years) & 53 & \\
\hline & & & 46 to 52 (Years) & 55 & \\
\hline & & & 52 to 58 (Years) & 62 & \\
\hline \multirow{5}{*}{2} & \multirow{5}{*}{$\begin{array}{l}\text { What is the highest level of education } \\
\text { you have completed? }\end{array}$} & \multirow{5}{*}{ B } & Metric & 115 & \multirow{5}{*}{450} \\
\hline & & & Intermediate & 60 & \\
\hline & & & Bachelor & 180 & \\
\hline & & & Masters & 92 & \\
\hline & & & $\mathrm{PhD}$ & 3 & \\
\hline \multirow{2}{*}{3} & \multirow{2}{*}{ Do you have valid driving license? } & \multirow{2}{*}{$\mathrm{C}$} & Yes & 370 & \multirow{2}{*}{450} \\
\hline & & & No & 80 & \\
\hline \multirow{4}{*}{4} & \multirow{4}{*}{ How many hours you drive daily? } & \multirow{4}{*}{$\mathrm{D}$} & 1 Hour & 122 & \multirow{4}{*}{450} \\
\hline & & & 2 Hours & 190 & \\
\hline & & & 3 Hours & 134 & \\
\hline & & & 4 Hours & 4 & \\
\hline \multirow{2}{*}{5} & \multirow{2}{*}{ Type of vehicle? } & & Motor Car & 288 & \\
\hline & & $\mathrm{E}$ & Motor Cycle & 162 & 450 \\
\hline 6 & Mostly when vou drive? & $\mathrm{F}$ & Peak Hours & 388 & 450 \\
\hline & & $\mathrm{F}$ & Non Peak Hours & 62 & 450 \\
\hline & Are you aware about traffic signs and & & Basic & 206 & \\
\hline 7 & Are you aware adout trannc signis and & G & Moderate & 229 & 450 \\
\hline & & & Excellent & 15 & \\
\hline & Are vou reoularly followed traffic sions & & No & 0 & \\
\hline 8 & Are you regularly tollowed traftic signs & $\mathrm{H}$ & Sometime & 439 & 450 \\
\hline & & & Every time & 11 & \\
\hline & Are you using personal safety & & Yes & 22 & \\
\hline 9 & $\begin{array}{l}\text { equipments during driving (Helmet, } \\
\text { Seat Belt etc.)? }\end{array}$ & $\mathrm{I}$ & No & 428 & 450 \\
\hline 10 & Have you ever been injured during & $\mathrm{J}$ & Yes & 388 & 450 \\
\hline 10 & driving? & J & No & 62 & 450 \\
\hline & & & Minor & 190 & \\
\hline 11 & If Yes, Injury type? & K & Moderate & 166 & 388 \\
\hline & & & Major & 32 & \\
\hline 12 & Is any traffic sign or symbols was & $\mathrm{I}$ & Yes & 290 & 388 \\
\hline 12 & posted at accident place? & $\mathrm{L}$ & No & 98 & 388 \\
\hline & & & Careless driving & 132 & \\
\hline & & & $\begin{array}{l}\text { Ignoring traffic } \\
\text { signs and symbols }\end{array}$ & 88 & \\
\hline 13 & Causes of accident? & M & $\begin{array}{l}\text { Mental distractions } \\
\text { from work }\end{array}$ & 44 & 388 \\
\hline & & & Taking shortcuts & 97 & \\
\hline & & & During overtaking & 27 & \\
\hline 14 & Have your any family member or & N & Yes & 28 & 150 \\
\hline 14 & relative or friend died in road accident? & $\mathrm{N}$ & No & 422 & 450 \\
\hline 15 & Which type of vehicle he or she was & O & Car & 12 & 28 \\
\hline & using when accident occur? & & Motor Cycle & 16 & 28 \\
\hline
\end{tabular}


Some interesting facts could be furnished form the analyzed data. First of all the highest level of education is graduation as responded while only $5 \%$ are agreed to use on personal protective equipments. Not only that, almost 50\% responded lying in the category of having initial knowledge of road safety. This leads towards the issue that the majority of road user is not sentient of traffic rules and regulations despite of educational background. Keeping in view of the gravity of issue, road safety should be the part of curriculum at different stages of education. According to the data, more than $90 \%$ persons agreed on the negligence of obeying traffic signs and in the same way direct relationship of more than $50 \%$ is achieved on the contributory factors of careless driving and ignoring traffic signs.

The interconnection in between issuance of driving license, road safety awareness, applicability and personal cure are tentatively judged in the above discussion. It could be more easily understood in the form of pie chart as follows.

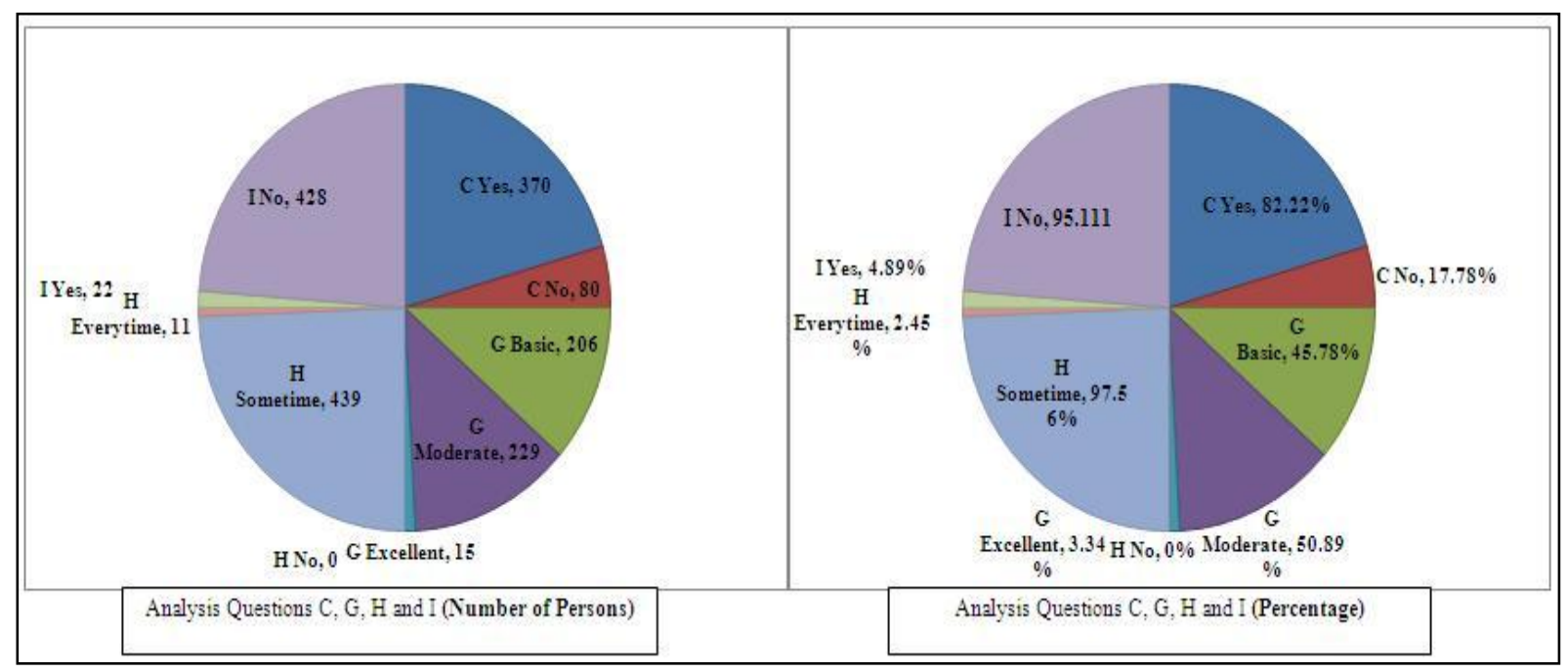

Fig. 3. Driving illiteracy rate analysis and avoidance personnel safety (Karachi city).

\section{Policy and Framework Evaluation for Road Safety}

Currently Pakistan has not organized any computerized data bank which keeps record of all the road accidents. Statistics for road crashes are based on the data provided by police agencies which is under reported [5]. There is an immense need of Policy and framework evaluation for the pre and post crash phase [6]. It is quite apparent from the author's statistical data that there is a quite risky operating traffic in Karachi city, the reason behind is that either domestic traffic policy is not appropriately put into practice or it might be outdated due to the highly populated and crowded traffic. An effective system is dependent on the road user training licensing and training programs designed in a manner that should enrich the requirements of vehicles quality, transport services and roads and public spaces. The whole dilemma is associated with the primary factors such as research, education, communication and secondary factors such as judicial action and accident control.

\section{Balanced between Three E's of Transportation}

As mentioned earlier, three Es of transportation need to be prioritized including Education, Engineering and Enforcement which is the main objective of this research study. Aims and objectives for these entities are clearly defined as follows:

Education:

Road users are to be introduced with their rights and limitations securing from the hazardous condition while providing a safe room for others as well.

Engineering:

Following the standard practices and improvement for all engineering works with the provision of safe and smart route network.

Enforcement: 
Preventing violation of the rules of the road by the road users by organizing a very effective enforcement agency.

\section{Recommendations}

With the orientation of title, the way forwards steps and recommendations include micro and macro level processes as follows:

- Road crash is not a infrastructure problem nor human issue, it should be taken as public health problem and on prior basis;

- Road crashes for different areas of Karachi should be categorized on the basis of road, human and vehicle contributory factors;

- Black roads and black spots of the entire city should be focused based on the severity indices;

- Organizations should play vital role in order to collect road accident data. In this connection standard practices should be adopted;

- Impact studies (before and after) should be prepared for future perspective while data should be monitored and checked on equal intervals;

- Public private partnership programs should be introduced for traffic accident data collection and manipulation;

- As per the existing structure, the local community police working on crash prevention should join hands with private agencies in order to achieve better accuracy;

- Road accident investigation program should be implemented in the existing system. On the availability of funds, standard practices should be molded;

- Road safety should be the part of curriculum at different levels of Education;

- Computerized and strict Enforcement action should be applied or it could be linked appropriately with NADRA database;

- New and updated Engineering standards should be designed prevailing the nature and traffic conditions of Pakistan;

- Each road user should be given the adequate importance while providing the infrastructure facilities;

- Efficient and effective emergency response vehicle (ERV) system could be furnished;

- Emergency centers should be deputed at approachable locations while they are to be identified based on the severity of area;

- Road safety policy formulation is the integrated step that provides the broader umbrella to above discussed points.

\section{Conclusion}

Traffic and road safety condition in Pakistan, is an issue in which very few organization and people are willing to do fruitful action for the future advancement. Recently other developing countries started to contribute in this activity through various means. One of the best examples is the decade action for road safety (2011-2020) in which a number of developing countries are enlisted and assigned with the substantial and proactive issue of traffic safety concern. Research exemplify that there are many obstacle due to which safety is not put into practice. In this incongruous condition, education and enforcement both are important stages. Experts, professionals and foreigners should play important roles in the effective training sessions. In conclusion, government should also provide adequate safety policies and train people. Transport agencies facing shortage of resources and funds; to achieve the best results funding in this sector should be increased for implementation of policy in a better way. In addition regulatory bodies such as Ministry of Information and Broadcasting, Capital City Traffic Police Karachi, Motor Vehicle Inspection Karachi and City District Government Karachi should plan and design a structure to review and judge the 
safety performance and level. The author strongly believes that there is an urgent need to adopt and implement lifesaving techniques and strategy, in this view this research study can be used as the benchmark or primary step.

\section{References}

[1] D. Mohan, and G. Tiwari, "Road safety in low Income countries: Issues and concern regarding technology transfer from high-income countries," Reflections on the Transfer of Traffic Safety Knowledge to Motorising Nations, Global Traffic Safety Trust, Vermont South, Australia, pp. 27-56. 1998.

[2] M. Saqib, K. Sheeraz, and M. Farooqui, "Development of guidelines for road safety audit in Pakistan: Case studies," Proceeding of the 3rd International Symposium on Infrastructure Engineering in Developing Countries (IEDC 2010), July 1-3, Karachi, Pakistan, pp. 141-151, 2010.

[3] S. Qureshi, "The fast growing megacity Karachi as a frontier of environmental challenges: Urbanization and contemporary urbanism issues," J. Geogr. Regional Plan., vol. 3, no. 11, pp. 306-321, 2010.

[4] G. Tiwari, D. Mohan, and N. Muhirad, The Way Forward: Transportation Planning and Road Safety, Macmillan India Ltd., New Delhi, 2005.

[5] B. Hanif, "Traffic hazards in Karachi," Pakistan Today, Jun 23, 2011.

Online at: http://www.pakistantoday.com.pk/2011/06/23/comment/traffic-hazards-in-karachi/

[6] A. Ahmed, "Road safety in Pakistan," National Road Safety Secretariat, Ministry of Communications, Government of Pakistan, June 21, 2007. Online at:

http://www.unescap.org/ttdw/roadsafety/Reports2007/Pakistan_RSpaper.pdf 